\title{
Evaluation of exposure to primary care clinics during Family Medicine residency: evidence from a training program in Riyadh, Saudi Arabia
}

\author{
MAMDOUH FALEH ALTHAGEEL 1, A, B, D, E, MOHAMMAD SHIBLY KHAN ${ }^{1, A-F}$, \\ ORCID ID: 0000-0002-1202-2122 \\ RIZWAN SULIANKATCHI ABDULKADER R, A, C-F, NOORULZAMAN KADHER MOHAIDEEN ${ }^{1, A-E}$,

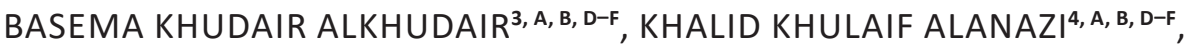 \\ YAZEED ABDULRAHMAN ALSULIMAN ${ }^{4, A, B, D-F}$
}

\footnotetext{
${ }^{1}$ King Salman bin Abdulaziz Hospital, First Health Cluster (C1), Riyadh, Saudi Arabia

${ }^{2}$ Department of Epidemiology and Biostatistics, ICMR National Institute of Epidemiology, Chennai, India

${ }^{3}$ Post Graduate Training Center for Family Medicine, Ministry of Health, Riyadh, Saudi Arabia

${ }^{4}$ Department of Public Health, General Directorate of Health Affairs in Riyadh Region, Ministry of Health, Riyadh, Saudi Arabia
}

A - Study Design, B - Data Collection, C - Statistical Analysis, D - Data Interpretation, E - Manuscript Preparation, F - Literature Search, G - Funds Collection

Summary Background. Evaluation is a crucial element to ensure the achievement of the program objectives, maintenance of training standards and to provide feedback for academic activities.

Objectives. We aimed to examine the extent and patterns of clinical exposure by family medicine residents in a residency training program while they carried out their clinical rotations in accredited urban primary health care centers in Riyadh, Saudi Arabia.

Material and methods. This study involved the Saudi Board of Family Medicine training program under the Department of Public Health, General Directorate of Health Affairs in Riyadh, Ministry of Health, Saudi Arabia. The study was based on a retrospective analysis of data collected during routine supervision of clinical training during family medicine rotations during six months period (November 2018-April 2019). Diagnoses recorded by the residents as free texts were converted to the closest medical diagnosis or 'presenting complaints' as per ICD-10. Cases attended are presented as percentages.

Results. During the study period, a total of 41,357 clinical encounters were recorded that included 4,952 clinical sessions. Diseases of the respiratory system were most commonly seen by the residents, accounting for $30 \%$ of total cases. Just twenty diagnoses/conditions accounted for approximately $77 \%(n=31,994)$ of the total clinical encounters. The five most common conditions were upper respiratory tract infections (16\%), vaccinations (12\%), diabetes mellitus unspecified $(9 \%)$ and essential hypertension (6\%).

Conclusions. Exposure to the primary care clinical cases reflected the disease pattern in the community at large. The residents were exposed to a low proportion of mental health and behavioral diseases, which are considered to be increasingly relevant in society. Key words: family practice, internship and residency, primary health care, Saudi Arabia.

Althageel MF, Khan MS, Abdulkader RS, Mohaideen NK, Alkhudair BK, Alanazi KK, Alsuliman YA. Evaluation of exposure to primary care clinics during family medicine residency: evidence from a training program in Riyadh, Saudi Arabia. Fam Med Prim Care Rev 2021; 23(3): 269-273, doi: https://doi.org/10.5114/fmpcr.2021.108187.

\section{Background}

Family medicine is a specialty that has the distinction of offering comprehensive care to a variety of beneficiaries in the community at a very local level [1]. By being the first point of care, the family physician has to deal with a wide range of clinical scenarios regardless of gender, age, disease, or clinical setting. In the new national model of care adopted by the Kingdom of Saudi Arabia, patient care has been envisaged based on a system of care that includes preventive and promotive care, maternal and child care, acute and urgent care, chronic care, planned care, and terminal care [2]. Because the family physician has an integrated role in all these systems, either as the sole provider or as a care coordinator [2], it is highly desirable to ensure proper exposure to primary medical encounters dur- ing a family medicine residency training period to improve their skills. Furthermore, patient preferences have been found to be significantly affected by family physician skill levels [3].

There are at least 50 clinical conditions listed in the family medicine curriculum as being a priority in the knowledge domain [4]. There is a lack of evidence regarding the length and breadth of clinical exposure for family medicine residents in Saudi Arabia. Evaluation is also a vital component of teaching and training to ensure the achievement of objectives and to maintain standards [5]. These objectives and standard are outlined in the curriculum for Saudi Board Family medicine. At the training program level, a special appointed committee supervises the clinical training of residents [4]. Apart from ensuring the smooth running of the clinical rotation, supervision of clinical training is also desirable to provide feedback for planning academic activities. 


\section{Objectives}

We aimed to examine the extent and patterns of clinical exposure obtained by both senior and junior level family medicine residents in a Family Medicine residency program run under the Ministry of Health, Riyadh, Saudi Arabia.

\section{Material and methods}

\section{Setting and participants}

The Family Medicine residency program has been established under the Department of Public Health in the General Directorate of Health Affairs, Riyadh. In this four-year program, a total of ninety-nine residents were distributed as follows: fourth year (08), third year (22), second year (32), and first year (38). Ten accredited primary health care centers (PHCs) were affiliated with the program for training the residents. The residents were posted in these PHCs as per their rotation schedule. This rotation schedule is drafted at the beginning of each academic session, following the SCFHS guidelines for training requirements. The recommended duration of family medicine rotations includes 12 weeks during the first, second, and third year and 42 weeks during the fourth year [3]. This study was conducted as a retrospective data analysis of data collected during the routine supervision of clinical training during the family medicine rotations.

\section{Data collection}

A structured form called the 'clinical supervision form' was used by the residents to document the cases seen by them during every clinical session and includes details, such as the main complaints/diagnosis and management, as well as other information. During each clinical session, the residents were posted under a trainer (family medicine specialist/consultant) who was responsible for supervising the clinical training. These trainers verified and approved these forms before submitting them to the program administration. Data over a period of six months (November 2018-April 2019) were analyzed.

\section{Statistical analysis}

Data from the clinical supervision forms were entered into MS Excel. Residents entered their findings as free texts which were then converted to the closest medical terminology as either a diagnosis or presenting clinical condition, following the International Classification of Diseases (ICD-10) coding. Garbage entries that could not be classified were discarded. The coding was performed by three trained ICD-10 coders to ensure accuracy and reliability. In the subsequent step, diagnoses and/or presenting complaints were pooled together under the relevant chapters of ICD-10. The results are presented as the frequency and percentages with a $95 \%$ confidence interval.

\section{Ethical considerations}

The study was approved by the Central Institutional Review Board, General Directorate of Research and Studies, Ministry of Health, Riyadh, Saudi Arabia.

\section{Results}

During the study period, 84 residents were posted in family medicine rotations across the 10 accredited primary health centers. A total of 41,357 cases were recorded during 4,952 clinical sessions, accounting for approximately 8 average cases per session. During the study period, the highest number of cases seen in any PHC was 5515, whereas the highest number of clinical sessions held in any PHC was 710.

\section{Distribution of cases observed from the major dise- ase groups in ICD-10}

More than $60 \%$ of the total encounters involved three major disease groups: diseases of the respiratory system, factors influencing health status and contact with health services (including vaccination, pre-school examination, and lab follow-up), and endocrine, nutritional, and metabolic diseases (Table 1).

Diseases of the respiratory system were the single most common group, accounting for approximately $30 \%$ of cases. Major diagnoses/complaints in this group included URTI (53.5\%), common cold (15.3\%), asthma (12.4\%), pharyngitis/sore throat $(12 \%)$, and others (6.8\%). 'Factors influencing health status and contact with health services, including vaccination, pre-school examination, and lab follow-up ranked second, accounting for approximately $17.8 \%$ of total cases. Major conditions recorded in this group included vaccination (67.9\%), pre-school check-ups (17\%), consultations/follow-ups for laboratory examinations (6\%), general health check-ups (2.9\%), and others (6.2\%).

Endocrine, nutritional, and metabolic diseases accounted for approximately $14.6 \%$ of cases. The highest proportion in this group was contributed by 'unspecified diabetes' (60.4\%), followed by diabetes with hypertension (32.3\%), whereas others included dyslipidaemia (1.9\%), thyroid disorder (1.4\%), and obesity (1.2\%). 'Symptoms, signs, and abnormal clinical and laboratory findings not elsewhere classified' accounted for $6.4 \%$ of cases. The major contributions in this group were from unspecified cough $(23 \%)$, headache $(16.1 \%)$, abdominal pain (13\%), and allergic skin rashes (12.3\%).

Diseases of the digestive system accounted for approximately $6.4 \%$ with acute gastroenteritis (40\%), acid peptic diseases (25\%), and IBS (18\%) being the most prominent. Diseases of the circulatory system accounted for $6.2 \%$, and the predominant condition in this group was hypertension (94\%). 'Diseases of the musculoskeletal system and connective tissue' constituted 5.5\% and the rest of the disease groups, and each contributed less than 5\%, as shown in Table 1.

Table 1. Level 1 disease groups as per ICD-10, seen by Family Medicine residents during November 2018-April 2019 ( $n=41357)$

\begin{tabular}{|l|l|l|l|}
\hline International classification of Diseases (ICD) Chapter & Frequency & Percentage (\%) & $95 \% \mathrm{Cl}$ \\
\hline Diseases of the respiratory system & 12693 & 30.69 & $30.3-31.1 \%$ \\
\hline $\begin{array}{l}\text { Factors influencing health status and contact with health services (including } \\
\text { vaccination, pre-school examination, lab follow up) }\end{array}$ & 7370 & 17.82 & $17.5-18.2 \%$ \\
\hline Endocrine, nutritional and metabolic diseases & 6044 & 14.61 & $14.3-14.9 \%$ \\
\hline $\begin{array}{l}\text { Symptoms, signs and abnormal clinical and laboratory findings, not elsewhere } \\
\text { classified }\end{array}$ & 2635 & 6.37 & $6.1-6.7 \%$ \\
\hline Diseases of the digestive system & 2626 & 6.35 & $6.1-6.6 \%$ \\
\hline Diseases of the circulatory system & 2542 & 6.15 & $5.9-6.4 \%$ \\
\hline Diseases of the musculoskeletal system and connective tissue & 2293 & 5.54 & $5.3-5.8 \%$ \\
\hline
\end{tabular}




\begin{tabular}{|l|l|l|l|}
\hline \multicolumn{3}{|l|}{ Table 1. Level 1 disease groups as per ICD-10, seen by Family Medicine residents during November 2018-April 2019 ( $\mathbf{4 1} 357)$} \\
\hline International classification of Diseases (ICD) Chapter & Frequency & Percentage (\%) & $95 \%$ Cl \\
\hline Diseases of the skin and subcutaneous tissue & 854 & 2.06 & $1.9-2.2 \%$ \\
\hline Diseases of the ear and mastoid process & 849 & 2.05 & $1.9-2.2 \%$ \\
\hline Injury, poisoning and certain other consequences of external causes & 829 & 2.00 & $1.9-2.1 \%$ \\
\hline Diseases of the genitourinary system & 672 & 1.62 & $1.5-1.7 \%$ \\
\hline Diseases of the eye and adnexa & 477 & 1.15 & $1.1-1.3 \%$ \\
\hline Mental, behavioural and neurodevelopmental disorders & 419 & 1.01 & $0.9-1.1 \%$ \\
\hline $\begin{array}{l}\text { Diseases of the blood and blood-forming organs and certain disorders involving } \\
\text { the immune mechanism }\end{array}$ & 322 & 0.78 & $0.7-0.86 \%$ \\
\hline Pregnancy, childbirth and the puerperium & 314 & 0.76 & $0.7-0.8 \%$ \\
\hline Certain infectious and parasitic diseases & 235 & 0.57 & $0.5-0.6 \%$ \\
\hline Diseases of the nervous system & 85 & 0.21 & $0.2-0.3 \%$ \\
\hline External causes of morbidity & 32 & 0.08 & $0.1-0.11 \%$ \\
\hline Neoplasms & 10 & 0.02 & $0.01-0.03 \%$ \\
\hline Congenital malformations, deformations and chromosomal abnormalities & 3 & 0.01 & $0-0.02 \%$ \\
\hline Certain conditions originating in the perinatal period & 1 & 0.004 & $0.9-1.1 \%$ \\
\hline
\end{tabular}

Table 2. Top twenty level 2 diagnosis/conditions dealt seen by Family Medicine residents during November 2018-April 2019 ( $n=41357)$

\begin{tabular}{|c|c|c|c|c|c|}
\hline Rank & ICD-10 Code & Diagnosis/condition & Frequency & Percentage (\%) & $95 \% \mathrm{Cl}$ \\
\hline 1. & J06.9 & URTI & 6790 & 16.42 & $16.1-16.8 \%$ \\
\hline 2. & Z28.9 & Vaccination & 5005 & 12.10 & $11.8-12.4 \%$ \\
\hline 3. & E14 & Diabetes Mellitus unspecified & 3651 & 8.83 & $8.5-9.1 \%$ \\
\hline 4. & 110 & Essential Hypertension & 2462 & 5.95 & $5.7-6.2 \%$ \\
\hline 5. & E11 & Type 2 Diabetes Mellitus with Hypertension & 1949 & 4.71 & $4.5-4.9 \%$ \\
\hline 6. & J00 & Common cold & 1937 & 4.68 & $4.5-4.9 \%$ \\
\hline 7. & J45.901 & Asthma & 1568 & 3.79 & $3.6-3.9 \%$ \\
\hline 8. & J02.9 & Acute pharyngitis & 1458 & 3.53 & $3.4-3.7 \%$ \\
\hline 9. & Z02.0 & Pre-school examination & 1256 & 3.04 & $2.9-3.2 \%$ \\
\hline 10. & K52.9 & Acute gastroenteritis & 1067 & 2.58 & $2.4-2.7 \%$ \\
\hline 11. & K30 & Acid Peptic Disorder & 679 & 1.64 & $1.5-1.8 \%$ \\
\hline 12. & R05 & Cough unspecified & 602 & 1.46 & $1.3-1.6 \%$ \\
\hline 13. & J03.90 & Tonsillitis & 593 & 1.43 & $1.3-1.5 \%$ \\
\hline 14. & M54.5 & Lower Back Ache & 483 & 1.17 & $1.1-1.3 \%$ \\
\hline 15. & M79.673 & Pain unspecified & 473 & 1.14 & $1.0-1.2 \%$ \\
\hline 16. & K58.9 & IBS & 465 & 1.12 & $1.0-1.2 \%$ \\
\hline 17. & Z00.00 & Blood Tests (not otherwise specified) & 448 & 1.08 & $0.9-1.2 \%$ \\
\hline 18. & R51 & Headache & 425 & 1.03 & $0.9-1.1 \%$ \\
\hline 19. & R10.9 & Abdominal pain & 345 & 0.83 & $0.7-0.9 \%$ \\
\hline 20. & T14.90 & Injury unspecified & 338 & 0.82 & $0.7-0.9 \%$ \\
\hline \multicolumn{3}{|l|}{ Total } & 31994 & $77.35 \%$ & $76.9-77.6 \%$ \\
\hline
\end{tabular}

Top twenty diagnoses/conditions attended by the trainee residents

The individual conditions/diagnoses were reported as recorded by the residents and analyzed individually against the total number of clinical encounters, as shown in Table 2. Just 20 diagnosis/conditions accounted for more than $77 \%(n=31,994)$ of total medical care encounters at the primary health care centers. Upper respiratory tract infection (URTI) accounted for approximately $16 \%$ of the total cases, followed by vaccination visits (12\%). Diabetes mellitus unspecified and essential hypertension ranked third and fourth, accounting for approximately $9 \%$ and $6 \%$, respectively. Among other diagnoses, each accounted for less than $5 \%$ of the total, as shown in Table 2.

\section{Discussion}

To our knowledge, no previous study in Saudi Arabia has documented the clinical exposure of family medicine residents in a primary care setting. Clinical exposure among family medi- 
cine residents is important for their performance. Karl Iglar et al. reported a moderate level of correlation between the number of cases observed by residents and resident performance as measured by 'in-training scores' [6]. Similarly, the outcomes from family medicine rotation have also been found to be affected by the percentage of cases discussed, as reported by Abu Zuhairah et al. [7]. In this study, we only described the qualitative aspects of clinical rotation in family medicine.

The variety of cases observed by the residents during the 6-month period covered most of the chapters in ICD-10 but with unequal representation. Respiratory diseases were found to be the most common group of clinical conditions. This was similar to that reported by several other authors [8-12]. In our study, this might have been further confounded because the data collection period corresponded with the seasonal influenza period.

Among the individual diagnoses/clinical conditions, diabetes (unspecified) ranked third, after respiratory diseases and vaccination visits, which were first and second, respectively. The 'Global burden of disease' estimates has stated a high blood glucose level as the second leading disease risk for females and third level of risk for males in Saudi Arabia [13].

Moreover, the proportions of diabetes and hypertension cases were corroborated with annual statistics for 2018, as reported by the Ministry of Health, Saudi Arabia. For instance, in Riyadh, approximately $11 \%$ patients attended a chronic disease clinic out of the total primary health care visits in the year 2018 [11]. The proportion of antenatal cases seen by residents was approximately $0.7 \%$, which is also comparable to the annual statistics from 2018, which reported ANC visits of approximately $0.8 \%$ of the total PHC visits in the year 2018 in Riyadh [14].
These family medicine residents were exposed to a low proportion of certain epidemiologically important categories of diseases. For instance, the behavioral and mental disease group accounted for only $1 \%$ of the total cases attended by the residents during the 6-month period. In contrast, in Saudi Arabia, the proportion of patients with mental illness has been estimated to be as high as one third of the total patients who obtain primary health care [15]. World Health Organization has stated that mental, neurological and substance use disorders account for approximately $14 \%$ of the global burden of disease [16]. This discrepancy might be because of the high proportion of such cases who visit a service clinic instead of training clinic. However, Karl Iglar et al. also noted that family medicine residents did not attend some of the diagnoses that are important for certification by family physicians of Canada during their 3-month study [6]

We reported only the descriptive component of the clinical exposure for this study. Of note, the diagnoses/clinical conditions were recorded by the residents as free text. It would have been more appropriate for the residents to record them directly as ICD codes or the International Classification of Primary Care (IPC) [17].

\section{Conclusions}

Overall, the residents were exposed to a range of clinical conditions reflecting the disease burden in the community. A system should be adopted at the program level to supervise and monitor proper exposure to primary care. Further studies should be carried be out to confirm our findings and to examine the relationship between clinical exposure and performance of residents.

Source of funding: This work was funded from the authors' own resources.

Conflicts of interest: The authors declare no conflicts of interest.

\section{References}

1. Bazemore A, Petterson S, Peterson LE, et al. More comprehensive care among family physicians is associated with lower costs and fewer hospitalizations. Ann Fam Med 2015; 13(3): 206-213.

2. Saudi Commission for Health Specialties. Saudi Board Family Medicine Curriculum. Riyadh: Saudi Commission for Health Specialties; 2020.

3. Verulava T, Dangadze B, Jorbenadze R, et al. The Gatekeeper Model: patient's view on the role of the family physician. Fam Med Prim Care Rev 2020; 22(1): 75-79.

4. Saudi Commission for Health Specialties. Saudi Board Family Medicine Curriculum. Riyadh: Saudi Commission for Health Specialties; 2016.

5. Morrison J. ABC of learning and teaching in medicine: Evaluation. BMJ 2003; 326(7385): 385-387.

6. Iglar K, Murdoch S, Meaney C, et al. Does clinical exposure matter? Pilot assessment of patient visits in an urban family medicine residency program. Can Fam Physician 2018; 64(1): 42-48.

7. Zuhairah AR, Al-Dawood KM, Khamis AH. Factors affecting Family Medicine residents' perception of achievement of training objectives. J Health Spec 2014; 2(3): 114

8. Salvi S, Apte K, Madas S, et al. Symptoms and medical conditions in 204912 patients visiting primary health-care practitioners in India: a 1-day point prevalence study (the POSEIDON study). Lancet Glob Health 2015; 3(12): 776-784.

9. Mash B, Fairall L, Adejayan O, et al. A morbidity survey of South African primary care. PloS ONE 2012; 7(3): e32358.

10. Wändell P, Carlsson AC, Wettermark B, et al. Most common diseases diagnosed in primary care in Stockholm, Sweden, in 2011. Fam Pract 2013; 30(5): 506-513.

11. Finley CR, Chan DS, Garrison S, et al. What are the most common conditions in primary care? Systematic review. Can Fam Physician 2018; 64(11): 832-840.

12. Britt H, Miller GC, Henderson J, et al. General practice activity in Australia 2015-16. General practice series no. 40. Sydney: Sydney University Press, 2016.

13. Memish ZA, Jaber S, Mokdad AH, et al. Burden of disease, injuries, and risk factors in the Kingdom of Saudi Arabia, 1990-2010. Prev Chronic Dis 2014; 11: 140176

14. Ministry of Health. Statistical Yearbook. 2018. Kingdom of Saudi Arabia. Available from URL: https://www.moh.gov.sa/en/Ministry/ Statistics/book/Documents/book-Statistics.pdf.

15. Al-Khathami AD, Ogbeide DO. Prevalence of mental illness among Saudi adult primary-care patients in Central Saudi Arabia. Saudi Med J 2002; 23(6): 721-724.

16. World Health Organization (2020). Mental Health Gap Action Programme (mhGAP) (cited 19.01.2021). Available from URL: https:// www.who.int/teams/mental-health-and-substance-use/mental-health-gap-action-programme.

17. World Health Organization. International Classification of Primary Care. Second edition (ICPC-2). Geneva: WHO. Available from URL: https://www.who.int/classifications/icd/adaptations/icpc2/en/. 
Tables: 2

Figures: 0

References: 17

Received: 11.01.2021

Reviewed: 19.02 .2021

Accepted: 13.03.2021

Address for correspondence: Mohammad Shibly Khan, MD

King Salman Hospital

First Central Health Cluster

Ministry of Health

Riyadh

Saudi Arabia

Tel.: +966 509435093

E-mail: shibly001@gmail.com 